\title{
AKTIVITAS ANTIBAKTERI JAMU MADURA SUBUR KANDUNGAN
}

\author{
Andik Wijayanto dan Romi Abrori \\ Jurusan Biologi, Fakultas Sains dan Teknologi, UIN Maulana Malik Ibrahim Malang \\ *Email korespondensi: wijayantoand@gmail.com
}

\begin{abstract}
Madurese traditional medicine (herbs) Subur Kandungan is a medicine that is widely used and produced in Madura that contains Curcuma zedoaria (Chrism.)Rosc., Kaempferia galanga L., Foeniculum vulgare Mill., and Centella asiatica (L.)Urb. highly favoredby the Indonesian community, especially women to improve reproductive health but have not been tested scientifically and standardization to ensure efficacy and safety. Initial stageis screening bioactive compound and then antibacterial activity assay with paper disc method. Clinical bacterial isolates such as Escherichia coli and Staphylococcus aureus were used as test organisms. The best treatment to inhibit the growth of E. Coli and S. aureusis $70 \%$ ethanol at a concentration of extract $1000 \mathrm{mg} / \mathrm{ml}$ with inhibition zone respectively $5 \mathrm{~mm}$ and $6.5 \mathrm{~mm}$. Although in crude extract form, Madurese traditional medicine (herbs) Subur Kandungan had inhibitory effect on the growth of the E.coli and S.aureus so this traditional medicine potential as an antibacterial agent. It is recommended that further work be done to identify the specific secondary metabolite compound that responsible for this effect, purify it, and standardize as same as a antibacterial drug.

Keyword: Madurese traditional medicine (herbs) Subur Kandungan, Antibacterial activity, $C$. zedoaria, $K$. galanga, F. vulgare, and C. asiatica
\end{abstract}

\section{PENDAHULUAN}

Ramuan tradisional atau lebih dikenal sebagai jamu sering digunakan oleh masyarakat Indonesia sebagai alternatif dalam menjaga kesehatan dan mengobati suatu penyakit selain berobat ke dokter dan menggunakan obat-obat sintetis. Data Riset Kesehatan Dasar 2010 menunjukkan $56 \%$ masyarakat Indonesia pernah mengkonsumsi jamu dan Jawa Timur mempunyai tingkat konsumsi jamu yang cukup tinggi yaitu $71,84 \%$. Tingkat konsumsi jamu yang cukup tinggi disebabkan jamu merupakan warisan nenek moyang dan manfaatnya dapat dirasakan langsung oleh konsumen yang sebagian besar $(61,87 \%)$ adalah wanita (Armas, 1995).

Diantara sekian banyak jenis jamu yang dikonsumsi wanita, sebagian besar adalah jamu Madura untuk kesehatan reproduksi (menyuburkan kandungan). Handayani dan Suharti (1999) menginventarisasi 19 produsen jamu di 4 kabupaten di Pulau Madura (Bangkalan, Sampang, Pamekasan dan Sumenep) dan ditemukan berbagai produk jamu untuk perawatan dan pengobatan kesehatan reproduksi termasuk untuk kesehatan ibu setelah melahirkan. Menurut Handayani (2003) pulau Madura merupakan daerah yang memiliki industri pengolahan jamu yang terbukti memiliki khasiat yang lebih baik jika dibandingkan dengan jamu Jawa, tetapi jamu Madura memiliki rasa yang lebih pahit jika dibandingkan dengan jamu Jawa.

Salah satu jamu Madura untuk kesehatan reproduksi (menyuburkan kandungan) yang banyak digunakan oleh masyarakat adalah jamu Subur Kandungan. Jamu ini berisi ekstrak $C$. zedoaria, $K$. galanga, $F$.vulgare, dan $C$. asiatica.

Penelitian sebelumnya telah dilakukan uji antibakteri dan terbukti mempunyai aktivitas antibakteri dari masing-masing spesies $C$. zedoaria (Bugno et al., 2007 dan Das dan Rahman 2012), K. galangal (Kochuthressia et al., 2012, Rao dan Kaladhar 2014), F.vulgare (Ruberto et al., 2000, Lo Cantore et al., 2004), dan C. asiatica (Taemchuay et al., 2009, Dash et al., 2011) tetapi belum pernah dilakukan uji antibakteri dalam bentuk ramuan/ jamu perpaduan ekstrak $C$. zedoaria, $K$. galanga, F.vulgare, dan C. asiatica.

Namun dalam pengembangan jamu Madura terdapat beberapa kendala, antara lain standarisasi sulit untuk dilakukan karena bahan baku sebagian besar dibeli dari pasar tradisional. Selain itu, dosis yang digunakan juga belum 
terstandarisasi dengan baik. Berdasarkan kondisi diatas, maka perlu dilakukan screening fitokimia (metabolit sekunder) dan analisis aktivitas antibakteri jamu Madura Subur Kandungan.

\section{BAHAN DAN METODE}

Bahan yang digunakan dalam penelitian ini adalah $C$. zedoaria, $K$. galanga, $F$. vulgare, $C$. asiatica, etanol p.a, aquades, metanol, larutan $\mathrm{HCl} 2 \%$, larutan metanol 50\%, logam $\mathrm{Mg}$, larutan $\mathrm{FeCl}_{3}$, larutan gelatin, reagen Dragendroff, reagen Meyer, pereaksi Lieberman Burchard, latutan $\mathrm{H}_{2} \mathrm{SO}_{4}$ pekat, larutan formaldehid 3\%, isolat $E$. coli dan $S$. aureus, media pertumbuhan bakteri Luria Broth (LB) dan Luria Agar (LA).

Alat yang digunakan dalam penelitian ini adalah oven, loyang, cawan petri, cawan penguap, desikator, neraca analitik, dan penjepit kayu, blender, gunting, dan ayakan 60 mesh, neraca analitik, kaca arloji, erlenmeyer $500 \mathrm{~mL}$, aluminium foil, shaker, gelas ukur $100 \mathrm{~mL}$, beaker glass $100 \mathrm{~mL}$, kertas saring, penyaring buchner, rotary evaporator, erlenmeyer 500 $\mathrm{mL}$, botol vial, desikator, tabung reaksi, bola hisap, rak tabung reaksi, pipet tetes, penjepit kayu, vortex dan pipet ukur $5 \mathrm{~mL}$, plat silika gel $\mathrm{F}_{254}$, bejana pengembang, Laminar Air Flow (LAF),dan lampu UV.

\section{Pembuatan Jamu.}

Sampel tanaman rizoma $C$. zedoaria, rizoma $K$. galanga, biji F.vulgare dan daun $C$. asiatica dicuci bersih dan dikeringanginkan. Selanjutnya sampel dipotong kecil-kecil dengan gunting atau pisau dan dikeringkan dengan oven pada suhu $30-37{ }^{\circ} \mathrm{C}$ selama $1-2$ jam. Kemudian sampel kering dihaluskan dengan blender sampai menjadi serbuk dan diayak dengan ayakan 60 mesh. Jamu Subur Kandungan dibuat dengan mencampurkan 4 macam bahan tanaman dengan komposisi masing-masing $25 \%$. Kemudian jamu tersebut digunakan sebagai sampel proses ekstraksi.

\section{Proses Ekstraksi}

Metode ekstraksi yang digunakan adalah metode maserasi dengan pelarut aquades, etanol $70 \%$, dan etanol 100\%. Serbuk jamu Subur Kandungan ditimbang sebanyak $60 \mathrm{~g}$, lalu diekstraksi dengan perendaman menggunakan $300 \mathrm{~mL}$ pelarut etanol selama 24 jam, kemudian dishaker selama 3 jam, selanjutnya disaring dan ampas yang diperoleh dimaserasi kembali dengan pelarut yang sama dan dilakukan sebanyak 3 kali pengulangan sampai filtratnya berwarna bening. Hasil penyaringan dilakukan evaporasi dengan rotary evaporator, pada suhu $40^{\circ} \mathrm{C}$ selama 30 menit. Hasil dari proses evaporasi kemudian disimpan pada suhu $4^{\circ} \mathrm{C}$ untuk selanjutnya dilakukan uji fitokimia.

\section{Uji Fitokimia}

Uji Alkaloid (Harbone, 1987). Ekstrak jamu Subur Kandungan diambil sebanyak 2 mg dan dimasukkan dalam tabung reaksi, ditambah $0,5 \mathrm{~mL} \mathrm{HCl} 2 \%$ dan larutan dibagi dalam dua tabung. Tabung I ditambahkan $0,5 \mathrm{~mL}$ reagen Dragendorff, tabung II ditambahkan $0,5 \mathrm{~mL}$ reagen Meyer. Jika tabung I terbentuk endapan jingga dan pada tabung II terbentuk endapan kekuning-kuningan, menunjukkan adanya alkaloid.

Uji Flavonoid (Indrayani et al., 2006). Ekstrak jamu Subur Kandungan diambil sebanyak $2 \mathrm{mg}$ dimasukkan dalam tabung reaksi kemudian dilarutkan dalam 1-2 mL metanol panas $50 \%$. Setelah itu ditambah logam $\mathrm{Mg}$ dan $0,5 \mathrm{~mL} \mathrm{HCl}$ pekat. Larutan berwarna merah atau jingga yang terbentuk, menunjukkan adanya flavonoid.

Uji Triterpenoid dan Steroid (Indrayani et al., 2006). Ekstrak jamu Subur Kandungan diambil sebanyak $2 \mathrm{mg}$ dimasukkan dalam tabung reaksi, dilarutkan dalam $0,5 \mathrm{~mL}$ kloroform lalu ditambah dengan $0,5 \mathrm{~mL}$ asam asetat anhidrat. Campuran ini selanjutnya ditambah dengan $1-2 \mathrm{~mL} \mathrm{H}_{2} \mathrm{SO}_{4}$ pekat melalui dinding tabung tersebut. Jika hasil yang diperoleh berupa cincin kecoklatan atau violet pada perbatasan dua pelarut menunjukkan adanya triterpenoid, sedangkan jika terbentuk warna hijau kebiruan menunjukkan adanya steroid.

Uji Saponin (Halimah, 2010) Ekstrak jamu Subur Kandungan diambil sebanyak $2 \mathrm{mg}$ dimasukkan dalam tabung reaksi ditambah air (1:1) sambil dikocok selama 1 menit, apabila menimbulkan busa ditambahkan 2 tetes $\mathrm{HCl} 1$ $\mathrm{N}$ dan dibiarkan selama 10 menit, bila busa yang terbentuk bisa tetap stabil maka ekstrak positif mengandung saponin.

Uji Tanin (Indrayani et al., 2006).Ekstrak jamu Subur Kandungan sebanyak $2 \mathrm{mg}$ 
dimasukkan kedalam tabung reaksi, kemudian ditambahkan dengan 2-3 tetes larutan $\mathrm{FeCl}_{3}$ $1 \%$. Jika larutan menghasilkan warna hijau kehitaman atau biru tinta, maka bahan tersebut mengandung tanin.

\section{Uji Aktivitas Antibakteri}

Bakteri yang diuji adalah bakteri normal yang terdapat pada saluran reproduksi wanita yaitu $E$. coli dan $S$. aureus.

Regenerasi Bakteri. Sebelum melakukan uji antibakteri, bakteri yang akan dipakai diregenerasi terlebih dahulu. Yang pertama dilakukan adalah membuat biakan agar miring yaitu menggoreskan biakan dari stok bakteri ke agar miring dengan media Luria Broth (LB) yang masih baru. Sebanyak 1ose koloni E. coli dan $S$. aureus diambil dari media penyimpanan dan disebarkan ke medium LB baru. Kemudian diinkubasi pada suhu $35-40^{\circ} \mathrm{C}$ selama $24-48$ jam.

Uji Aktivitas dengan Metode Difusi Cakram Kertas (Paper Disc). Biakan ditanam satu ose pada media padat dalam cawan Petri, selanjutnya diratakan sampai kering menggunakan kaca speader. Cakram kertas dengan diameter 5,5 $\mathrm{mm}$ dibasahi dengan ekstrak jamu Madura Subur Kandungan dengan konsentrasi $0 \mathrm{mg} / \mathrm{ml}, 100 \mathrm{mg} / \mathrm{ml}, 500 \mathrm{mg} / \mathrm{ml}$, dan $1000 \mathrm{mg} / \mathrm{ml}$. Selanjutnya diinkubasi pada suhu $37^{0}$ C selama 24 jam kemudian didokumentasikan. Antibiotik tetrasiklin digunakan sebagai pembanding (kontrol positif) dengan konsentrasi $50 \mathrm{mg} / \mathrm{ml}$. Antibiotik ini dipilih karena telah teruji sensitif terhadap $E$. coli dan S. aureus.

\section{HASIL DAN PEMBAHASAN}

\section{Uji Fitokimia JamuSubur Kandungan}

Pengujian fitokimia dilakukan untuk mengetahui senyawa aktif yang terkandung dalam jamu Madura Subur Kandungan. Hasil pengujian fitokimia dapat dilihat pada Tabel1.

Tabel 1. Hasil Uji Fitokimia jamu Madura Subur Kandungan

\begin{tabular}{lc}
\hline $\begin{array}{l}\text { Penapisan } \\
\text { fitokimia }\end{array}$ & Hasil \\
\hline Flavonoid & Positif (++) \\
\hline Alkaloid & Positif (++) \\
\hline Saponin & Negatif (-) \\
\hline Tanin & Negatif (-) \\
\hline
\end{tabular}

Senyawa yang terdapat dalam jamu Madura Subur Kandungan adalah senyawa golongan flavonoid dan alkaloid.Senyawa golongan flavonoid dan alkaloid ini telah terbukti berpotensi sebagai senyawa antibakteri (Nazrul et al., 2002, Saravanakumar et al., 2009, Ozcelik et al., 2011).

\section{Uji Aktivitas Antioksidan Jamu Subur Kandungan}

Hasil pengamatan aktivitas antibakteri jamu Subur Kandungan terhadap bakteri E. coli dan $S$. aereus dengan beberapa konsentrasi pelarut yang digunakan disajikan pada tabel 2, gambar 2 dan3. Jenis dan konsentrasi pelarut 
Tabel 2 Aktivitas antibakteri jamu Subur Kandungan terhadap bakteri E. coli dan S. aereus dengan beberapa konsentrasi pelarut

\begin{tabular}{|c|c|c|c|c|c|c|c|}
\hline \multirow{3}{*}{ Pelarut } & \multirow{3}{*}{$\begin{array}{l}\text { Spesies } \\
\text { Bakteri }\end{array}$} & \multirow{3}{*}{ Ulangan } & \multicolumn{5}{|c|}{ Zona Hambat (mm) pada perlakuan } \\
\hline & & & \multicolumn{4}{|c|}{ Jamu Subur Kandungan } & \multirow{2}{*}{$\begin{array}{c}\text { Tetrasiklin } \\
50 \mathrm{mg} / \mathrm{ml}\end{array}$} \\
\hline & & & $\begin{array}{c}0 \\
\mathrm{mg} / \mathrm{ml}\end{array}$ & $\begin{array}{c}100 \\
\mathrm{mg} / \mathrm{ml}\end{array}$ & $\begin{array}{c}500 \\
\mathrm{mg} / \mathrm{ml}\end{array}$ & $\begin{array}{c}1000 \\
\mathrm{mg} / \mathrm{ml}\end{array}$ & \\
\hline \multirow{8}{*}{$\begin{array}{c}\text { Air } \\
\text { destilata }\end{array}$} & \multirow{4}{*}{ E. coli } & 1 & 0 & 2 & 0 & 3 & 16 \\
\hline & & 2 & 0 & 1.5 & 0.75 & 2 & 16 \\
\hline & & $\begin{array}{l}\text { Rata- } \\
\text { rata }\end{array}$ & 0 & 1.75 & 0.375 & 2.5 & 16 \\
\hline & & STDEV & 0.00 & 0.35 & 0.53 & 0.71 & 0.00 \\
\hline & \multirow{4}{*}{$\begin{array}{c}\mathrm{S} . \\
\text { aureus }\end{array}$} & 1 & 0 & 2.5 & 4 & 5 & 15.5 \\
\hline & & 2 & 0 & 1 & 2 & 3 & 7 \\
\hline & & $\begin{array}{c}\text { Rata- } \\
\text { rata }\end{array}$ & 0 & 1.75 & 3 & 4 & 11.25 \\
\hline & & STDEV & 0.00 & 1.06 & 1.41 & 1.41 & 6.01 \\
\hline \multirow{8}{*}{$\begin{array}{c}\text { Etanol } \\
70 \%\end{array}$} & \multirow{4}{*}{ E. coli } & 1 & 0 & 1.5 & 2 & 5 & 17.5 \\
\hline & & 2 & 0 & 3.5 & 4 & 5 & 15 \\
\hline & & $\begin{array}{l}\text { Rata- } \\
\text { rata }\end{array}$ & 0 & 2.5 & 3 & 5 & 16.25 \\
\hline & & STDEV & 0.00 & 1.41 & 1.41 & 0.00 & 1.77 \\
\hline & \multirow{4}{*}{$\begin{array}{c}\text { S. } \\
\text { aureus }\end{array}$} & 1 & 0 & 6.5 & 4 & 6 & 10 \\
\hline & & 2 & 0 & 4 & 4 & 7 & 11 \\
\hline & & $\begin{array}{c}\text { Rata- } \\
\text { rata }\end{array}$ & 0 & 5.25 & 4 & 6.5 & 10.5 \\
\hline & & STDEV & 0.00 & 1.77 & 0.00 & 0.71 & 0.71 \\
\hline \multirow{8}{*}{$\begin{array}{l}\text { Etanol } \\
100 \%\end{array}$} & \multirow{4}{*}{ E. coli } & 1 & 0.5 & 5 & 4 & 4 & 21 \\
\hline & & 2 & 0 & 3 & 3 & 5 & 20 \\
\hline & & $\begin{array}{l}\text { Rata- } \\
\text { rata }\end{array}$ & 0.25 & 4 & 3.5 & 4.5 & 20.5 \\
\hline & & STDEV & 0.35 & 1.41 & 0.71 & 0.71 & 0.71 \\
\hline & \multirow{4}{*}{$\begin{array}{c}\text { S. } \\
\text { aureus }\end{array}$} & 1 & 0 & 0.5 & 1 & 3 & 17 \\
\hline & & 2 & 0 & 0.5 & 0.5 & 1 & 16 \\
\hline & & $\begin{array}{c}\text { Rata- } \\
\text { rata }\end{array}$ & 0 & 0.5 & 0.75 & 2 & 16.5 \\
\hline & & STDEV & 0.00 & 0.00 & 0.35 & 1.41 & 0.71 \\
\hline
\end{tabular}




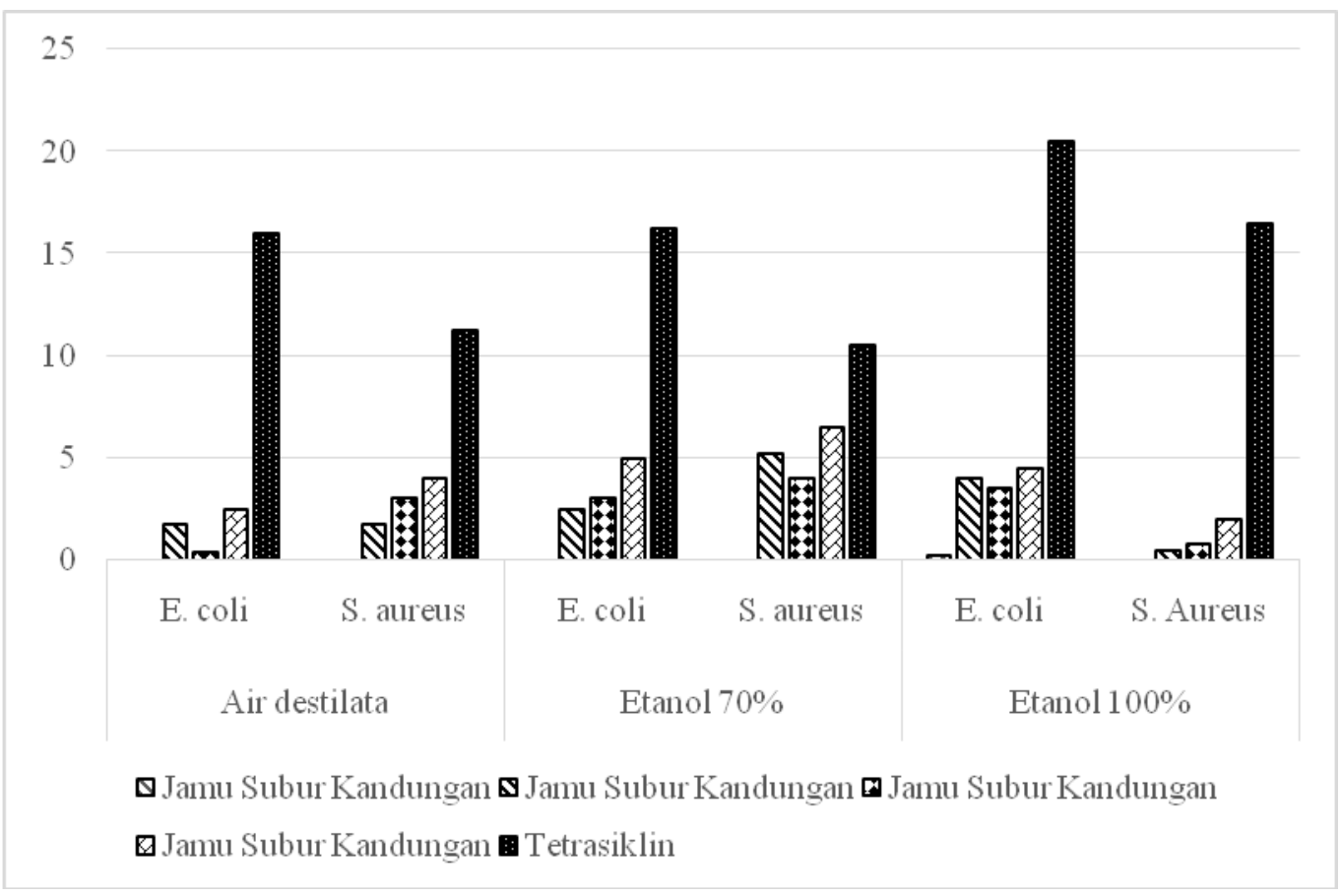

Gambar 2 Aktivitas antibakteri jamu Subur Kandungan terhadap bakteri E. coli dan S. aereus dengan beberapa jenis dan konsentrasi pelarut

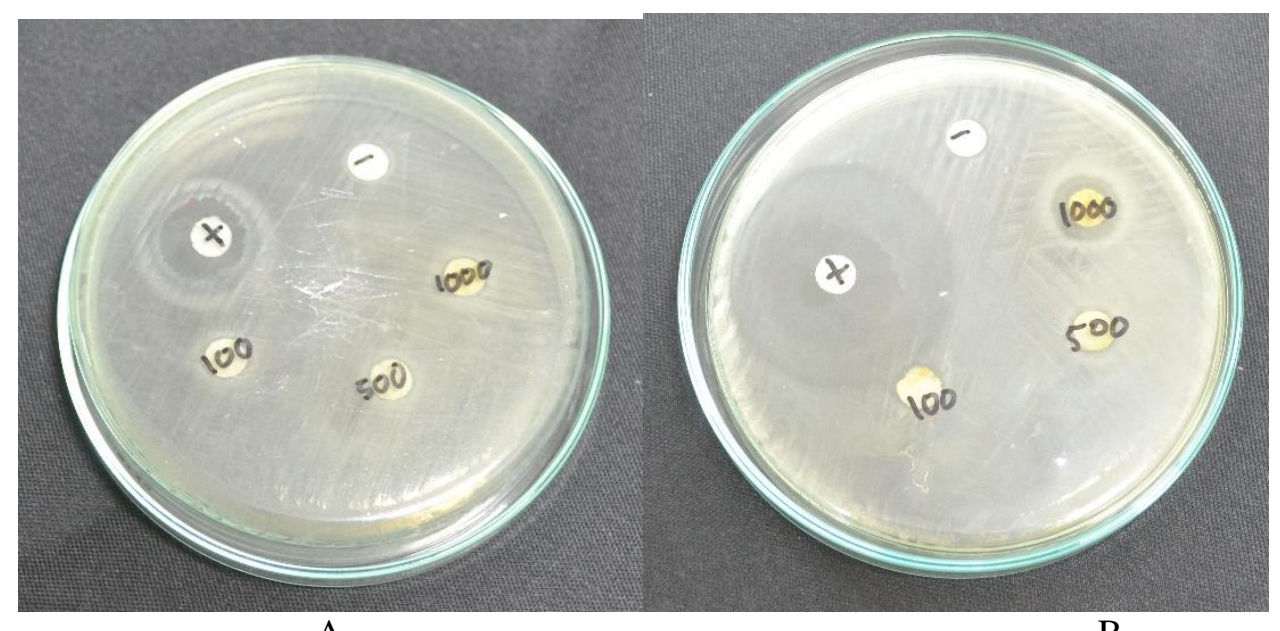

A

B

Gambar 3 Zona hambat jamu Subur Kandungan konsentrasi $0 \mathrm{mg} / \mathrm{ml}$ (kontrol negatif), $100 \mathrm{mg} / \mathrm{ml}$, $500 \mathrm{mg} / \mathrm{ml}$, dan $1000 \mathrm{mg} / \mathrm{ml}$ serta tetrasiklin $50 \mathrm{mg} / \mathrm{ml}$ (kontrol positif) dengan pelarut etanol $100 \%$ terhadap terhadap pertumbuhan bakteri E. coli (A) dan S. aureus (B). 
terbaik yang memiliki aktivitas penghambatan pertumbuhan bakteri E. coli maupun $S$. aereus adalah pelarut etanol $70 \%$. Dari semua perlakuan konsentrasi jamu Subur Kandungan yang digunakan, yaitu $0 \mathrm{mg} / \mathrm{ml}, 100 \mathrm{mg} / \mathrm{ml}, 500 \mathrm{mg} / \mathrm{ml}$, dan $1000 \mathrm{mg} / \mathrm{ml}$; konsentrasi terbaik yang menunjukkan daya hambat maksimum adalah pada konsentrasi $1000 \mathrm{mg} / \mathrm{ml}$ dengan segala jenis pelarut.

Daya hambat ini lebih kecil daripada daya hambat antibiotik tetrasiklin yang digunakan sebagai kontrol +. Hal ini wajar terjadi karena tetrasiklin yang digunakan merupakan senyawa bioaktif murni sedangkan ekstrak jamu yang digunakan masih dalam bentuk crude (ekstrak kasar). Meskipun dalam bentuk ekstrak kasar, jamu telah mempunyai kemampuan daya hambat terhadap pertumbuhan bakteri $E$. coli dan $S$. aereus sehingga jamu Subur Kandungan ini berpotensi sebagai antibakteri dan perlu dilakukan screening dan isolasi senyawa bioaktif serta uji antibakteri lanjutan dengan menggunakan bakteri-bakteri patogen yang terkait kesehatan reproduksi wanita seperti Neisseria gonorrhoeae dan Trichomonas vaginalis.

\section{SIMPULAN}

Senyawa kimia yang terkandung dalam jamu Madura Subur Kandungan adalah golongan flavonoid dan alkaloid. Senyawa ini diduga berperan aktif dalam aktivitas antibakteri.

Daya hambat terbaik ekstrak terhadap pertumbuhan bakteri E. coli dan S. aereus pada perlakuan pelarut etanol $70 \%$ pada konsentrasi $1000 \mathrm{mg} / \mathrm{ml}$ dengan zona hambat masing-masing $5 \mathrm{~mm}$ dan $6.5 \mathrm{~mm}$. Meskipun dalam bentuk ekstrak kasar, jamu ini telah mempunyai kemampuan daya hambat terhadap pertumbuhan bakteri E. coli dan $S$. aereus sehingga jamu Subur Kandungan ini berpotensi sebagai antibakteri.

\section{UCAPAN TERIMAKASIH}

Kami ucapkan terimakasih kepada LP2M UIN Maulana Malik Ibrahim Malang atas dukungan dana penelitian dan Tim Riset Biofarmaka FST UIN Maulana Malik Ibrahim Malang atas kerjasamanya.

\section{DAFTAR PUSTAKA}

Armas EJ. 1995. Learning Together. A woman's Story. In: Learning about Sexuality. A Practical Beginning. Editor: Sondra Zeidenstein and Kristen Moore. New
York : The Population Council International Women's Health Coalition.

Bugno A, Nicoletti MA, Almodovar AAB, Pereira TC, Auricchio MC. 2007. Antimicrobial efficacy of Curcuma zedoaria extract as assessed by linear regression compared with commercial mouthrinses. Brazilian $J$ of Microbiol 38:440-445.

Das K dan Rahman MA. 2012. Analgesic and microbial activities of Curcuma zedoaria. Int J Pharm Pharm Sci 4(5):322-328.

Dash BK, Faruquee HM, Biswas SK, Alam MK, Sisir SM, Prodhan UK. 2011. Antibacterial and Antifungal Activities of Several Extracts of Centella asiatica L. against Some Human Pathogenic Microbes. Life Sci and Med Research2011:1-5.

Halimah N. 2010. Uji Fitokimia dan Uji Toksisitas Ekstrak Tanaman Antinganting (Acalypha indica L.) terhadap Larva Udang Artemia salina Leach. Skripsi. Malang: UIN Maulana Malik Ibrahim Malang.

Handayani L. 2003. Membedah Rahasia Ramuan Madura. Jakarta: Agromedia Pustaka Press.

Handayani L dan Suharti S. 1999. Industri Kecil Obat Tradisional di Madura. Medika 5: 290-295.

Harborne JB. 1987. Metode Fitokimia: Penuntun Cara Modern Menganalisis Tumbuhan Terbitan Kedua. Bandung : ITB Press.

Indrayani L, Soetjipto H, Sihasale L. 2006. Skrining Fitokimia dan Uji Toksisitas Ekstrak Daun Pencut Kuda (Stachytarpheta jamacencis L. Vahl) terhadap Larva Udang Artemia salina Leach. J of Sci. 12: 57-61.

Kementrian Kesehatan 2010. Riset Dasar Kesehatan 2010.Jakarta: Kementrian Kesehatan Republik Indonesia Press.

Kochuthressia KP, Britto SJ, Jaseentha MO, Raphael R. 2012. In vitro antimicrobial evaluation of Kaempferia galanga L. rhizome extract. Am. J. Biotechnol. Mol. Sci. 2(1):1-5.

Lo Cantore P, Iacobellis NS, De Marco A, Capasso F, Senatore F. 2004. Antibacterial activity of Coriandrum sativum L. and Foeniculum vulgare Miller var. vulgare (Miller) essential 
oils.J Agric Food Chem. 52(26):78627866.

Nazrul ISK, Gray AI, Waterman PG, Ahasan M. 2002. Screening of eight alkaloids and ten flavonoids isolated from four species of the genus Boronia (Rutaceae) for antimicrobial activities against seventeen clinical microbial strains. Phytother Res.16(7):672-4.

Ozcelik B, Kartal M, Orhan I. 2011. Cytotoxicity, antiviral and antimicrobial activities of alkaloids,

flvonoids, and phenolic acids. Pharm Biol 49(4):396-402.

Rao RV dan Kaladhar DSVGK. 2014. Antioxidant and Antimicrobial Activities of RhizomeExtracts of Kaempferia galanga. World $J$ of Pharmacy and Pharmaceutical Sci 3(5):1180-1189.

Ruberto G, Baratta MT, Deans SG, Dorman HJ. 2000. Antioxidant and antimicrobial activity of Foeniculum vulgare and Crithmum maritimum essential oils. Planta Med 66(8):687-693.

Saravanakumar A, Venkateshwaran K, Vanitha J, Ganesh M, Vasudevan M, Sivakumar T. 2009. Evaluation of antibacterial activity, phenol and flavonoid contents of Thespesia populnea flower extracts. Pak J Pharm Sci. 22(3):282-6.

Taemchuay D, Rukkwamsuk T, Sakpuaram T, Ruangwises N. 2009. Antibacterial Activity of Crude Extracts ofCentella asiatica against Staphylococcus aureusin Bovine Mastitis. Kasetsart Veterinarians 19(3):119-128. 